\title{
ESTUDO E ANÁLISE DE INVESTIMENTOS EM UMA MICROCERVEJARIA ARTESANAL NO MUNICÍPIO DE SANTA MARIA ${ }^{1}$
}

\author{
STUDY AND ANALYSIS OF INVESTMENTS IN A \\ MICROBREWERY IN THE MUNICIPALITY OF SANTA MARIA
}

\section{Andressa Escarban Donatto ${ }^{2}$, Tiago Bessega ${ }^{3}$, Leandro Ribeiro Fontoura ${ }^{4}$, Liana da Silva Fernandes ${ }^{4}$ e Leonardo Fantinel $^{5}$}

\section{RESUMO}

O Brasil destaca-se a nível mundial quando se trata de produção de cerveja, sendo o terceiro maior produtor. Em decorrência disso, o consumo que também é em larga escala, acabou gerando uma nova prática que vem crescendo com o passar dos anos e levando os consumidores a se aventurarem na produção da sua própria cerveja, conhecida hoje como cerveja artesanal. Deste modo, surgiu uma nova oportunidade de empreendimento possivelmente lucrativo, que são as microcervejarias. Nesse contexto, o objetivo deste trabalho é estudar e analisar a viabilidade econômico-financeira para abertura de uma microcervejaria sob duas óticas diferentes: o modelo de fabricação própria e terceirização. Para isso foram utilizados vários indicadores de viabilidade, como o Valor Presente Líquido (VPL), Taxa Interna de Retorno (TIR), Demonstrativo de Resultado do Exercício (DRE) e Payback. A realização deste trabalho deu-se através de uma abordagem quantitativa a partir de um estudo de caso juntamente com a pesquisa bibliográfica, que demonstrou ser mais viável para o modelo de terceirização da produção.

Palavras-chave: Viabilidade econômica, produção de cerveja, terceirização, VPL, TIR.

\section{ABSTRACT}

Brazil stands out in the world when it comes to beer production, being the third largest producer. As a result, the consumption is also on a large scale, resulting in a new practice that has grown over the years and leads consumers to venture into the production of their own beer, known today as craft beer. Therefore, a new opportunity for a potentially lucrative enterprise, microbrewery, has emerged. In this context, the objective of this work is to study and analyze the economic-financial viability to open a microbrewery under two different perspectives, the own manufacturing and outsourcing models. For this purpose, several viability indicators were used, such as Net Present Value (NPV), Internal Rate of Return (IRR), Income Statement of Income (DRE) and Payback. The accomplishment of this work was done through a quantitative approach based on a case study along with bibliographical research, which proved to be more viable for the outsourcing model of production.

Keywords: Economic viability, beer production, outsourcing, NPV, IRR.

\footnotetext{
${ }^{1}$ Trabalho Final de Graduação II.

${ }^{2}$ Acadêmica do Curso de Engenharia Química - Universidade Franciscana. E-mail: andressadonatto@outlook.com

${ }^{3}$ Químico - Universidade Federal de Santa Maria. E-mail: tiagobessega@gmail.com

${ }^{4}$ Professores colaboradores dos Cursos de Matemática e Engenharia Química - Universidade Franciscana. E-mail: leandro.fontoura@ufn.edu.br; liana@ufn.edu.br

${ }^{5}$ Orientador - Universidade Franciscana. E-mail: leonardofantinel@ufn.edu.br
} 


\section{INTRODUÇ̃̃O}

Há milhares de anos, a fermentação foi descoberta pelos homens, mais precisamente por monges. Suspeita-se que essa descoberta deu-se através de uma preparação de pão que não obteve êxito, formando assim um líquido fermentado o qual era considerado sagrado pelos povos antigos. Essa suposição se justifica devido a algumas matérias primas da cerveja serem as mesmas da panificação, tais como os grãos de cereais e a levedura (MORADO, 2017).

No Brasil, a cerveja chegou junto com a vinda da família real portuguesa em 1808 (MORADO, 2017) e, desde então, se popularizou, tornando-se uma das bebidas mais apreciadas no país. Devido a sua disseminação e seu elevado consumo, o Brasil destaca-se pela grande produção de cerveja e pela quantidade de cervejarias e microcervejarias, espalhadas em todo o seu território, totalizando em 889. Tais empreendimentos, atualmente, estão distribuídos em 479 municípios ao longo do território nacional, representando cerca de $10 \%$ de toda a extensão do nosso país (MAPA, 2019).

O estado do Rio Grande do Sul destaca-se não só em termos quantitativos de cervejarias existentes, como sendo o maior produtor a nível nacional (MAPA, 2019), mas também em termos qualitativos devido à grande produção de cervejas artesanais provenientes das microcervejarias. No ano de 2017 haviam 142 cervejarias e microcervejarias registradas, e no ano seguinte esse número passou para 186, retratando um aumento de 31\% (MAPA, 2019).

As microcervejarias buscam sempre um cuidado para com a qualidade de suas cervejas. Para que isso ocorra, uma de suas características é a produção em pequena escala, com ingredientes selecionados, cujo produto final é uma cerveja com qualidade superior, sendo conferida a designação de "cervejas especiais". Neste caso, as cervejas artesanais estão se popularizando muito rapidamente, o que demonstra ser um cenário favorável para um futuro empreendimento lucrativo, devido ao seu crescimento.

Considerando que a maioria dos novos negócios que surgem no país são de micro e pequenos empresários, observa-se a necessidade da realização de um estudo de viabilidade econômico-financeira para projeção de um bom plano de negócios. A importância da análise de viabilidade se dá pelo fato dela ser uma aliada essencial para a tomada de decisão, tanto para abertura de um novo negócio; como também para a permanência do mesmo.

Nesse contexto, o objetivo deste trabalho é estudar e analisar a viabilidade econômico-financeira de produção e terceirização de uma microcervejaria localizada no município de Santa Maria - RS, a partir da coleta de dados e avaliação dos indicadores de investimentos. 


\section{REVISÃO BIBLIOGRÁFICA}

\section{INVESTIMENTO INICIAL}

Os investimentos iniciais englobam todos os gastos que serão necessários para a montagem e abertura de um negócio, como imóveis, veículos, instalações, maquinário, móveis, utensílios, entre outros.

As Tabelas 1 e 2 abaixo mostram a diferença entre os investimentos iniciais de fabricação própria e de terceirização da produção.

Tabela 1 - Investimentos iniciais para o modelo de fabricação própria.

\begin{tabular}{|cccc}
\hline Equipamento & Capacidade & Custo unitário (R\$) & Custo total (R\$) \\
\hline Moinho & $200 \mathrm{~kg} / \mathrm{h}$ & $2.800,00$ & $2.800,00$ \\
\hline Cozinha & $500 \mathrm{~L}$ & $54.425,45$ & $54.425,45$ \\
\hline Sistema aquecimento & & $16.200,00$ & $16.200,00$ \\
\hline Aerador & & 915,00 & 915,00 \\
\hline Chaminé & & 800,00 & 800,00 \\
\hline Trocador de calor & & $5.680,00$ & $5.680,00$ \\
\hline Sistema de frio & & $8.700,00$ & $8.700,00$ \\
\hline Enchedor de garrafa & & $4.100,00$ & $4.100,00$ \\
\hline Arrolhador & & $1.800,00$ & $1.800,00$ \\
\hline Bancada & $2.400,00$ & $2.400,00$ \\
\hline Bomba & $500 \mathrm{~L}$ & $2.100,00$ & $2.100,00$ \\
\hline Tanque fermentação & & $16.150,00$ & $32.300,00$ \\
\hline Investimento Capital de Giro & & $45.375,00$ & $45.375,00$ \\
\hline Criação página WEB & & $1.200,00$ & $1.200,00$ \\
\hline Computador & & $2.000,00$ & $2.000,00$ \\
\hline Veículo & & $26.000,00$ & $26.000,00$ \\
\hline
\end{tabular}

Fonte: Adaptado de DELGADO, 2016.

Tabela 2 - Investimento iniciais para o modelo de terceirização da produção.

\begin{tabular}{|ccc|}
\hline Equipamento & Custo unitário (R\$) & Custo total (R\$) \\
\hline Investimento Capital de Giro & $37.812,50$ & $37.812,50$ \\
Criação página WEB & $1.200,00$ & $1.200,00$ \\
Computador & $2.000,00$ & $2.000,00$ \\
Veículo & $26.000,00$ & $26.000,00$ \\
& & $67.012,50$ \\
\hline
\end{tabular}

Fonte: Adaptado de DELGADO, 2016.

\section{CUSTOS E DESPESAS}

No ramo dos negócios, custos e despesas são considerados saídas de caixa, porém, há algumas diferenças empregadas aos seus conceitos. 
Os custos são os gastos equivalentes a bens ou serviços empregados na produção de outros bens e serviços, ou seja, estão ligados diretamente ao produto final (MARTINS, 2003). Segundo o autor as despesas são gastos relacionados com as manutenções da empresa e com os gastos administrativos, estando indiretamente ligadas a operação da produção.

\section{FLUXO DE CAIXA}

No entendimento de Hirschfeld (2000), fluxo de caixa éÉ a avaliação das entradas e saídas monetárias no decorrer do tempo, o controle e reconhecimento das despesas e receitas a fim de ter o conhecimento dos resultados financeiros.

Para construir o fluxo de caixa, as operações monetárias devem ser devidamente anotadas e, o mesmo, pode ser representado de duas maneiras, pela representação analítica e por diagrama, como está sendo demonstrado na Tabela 3 e na Figura 1 abaixo, respectivamente.

Tabela 3 - Representação do Fluxo de Caixa Analítico.

\begin{tabular}{cc}
\hline Mês & Fluxo de caixa (R\$) \\
\hline 0 & $-1.500,00$ \\
1 & 0,00 \\
2 & 500,00 \\
3 & $1.000,00$ \\
4 & $-600,00$ \\
\hline 5 & 0,00 \\
6 & 700,00 \\
\hline Fonte: Construção do autor.
\end{tabular}

Figura 1 - Representação do Fluxo de Caixa por diagrama.

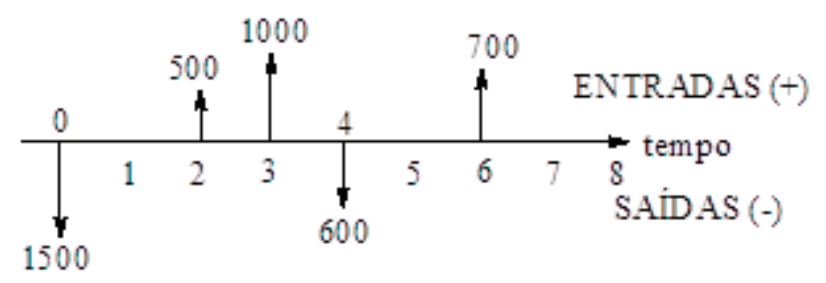

Fonte: ROCHA et al., 2015.

Todo o valor recebido, os lucros e economias feitas são fluxos positivos. Em contrapartida, as despesas, dívidas pendentes, aplicação de dinheiro e o custo dessa aplicação são considerados fluxos negativos. Diante disso, o propósito da construção de um fluxo de caixa é promover a saúde financeira do negócio e potencializar o lucro, visto que há possibilidade de previsão de possíveis ganhos e perdas. 
A Taxa Mínima de Atratividade (TMA) é estabelecida como a taxa mínima de juros que um investidor pode requisitar como medida, para que o investimento seja atrativo.

Para a realização do cálculo da taxa, Damodaran (2010) adverte que devem ser considerados três fatores que podem afetar o seu valor, como:

a) Custo de oportunidade: para investimentos que não apresentam riscos, como a Caderneta de Poupança, refletindo o retorno mínimo obtido;

b) Risco do negócio: o risco da ação deve ser proporcional a sua remuneração, como Bolsa de Valores.

c) Prêmio pela liquidez: eficácia em sair rapidamente de uma posição no mercado para adotar outra.

\section{VALOR PRESENTE LÍQUIDO (VPL)}

O Valor Presente Líquido (VPL) é um método de análise dos fluxos de caixa, que calcula o valor presente inicial a partir das entradas e saídas em um determinado período, visto que sua importância se dá pelo fato de uma quantia recebida no futuro não ter o mesmo valor monetário dessa quantia no presente, devido às taxas aplicadas (QUINTANELLA, 2011).

Pode ser calculado conforme a Equação (1) (VIEIRA SOBRINHO, 2011):

$$
V P L=-F C o+\sum_{j=1}^{n} \frac{F C j}{(1+i)^{j}}
$$

Onde:

$F C o=$ fluxo de caixa inicial; $n=$ número do período envolvido; $i=$ taxa de desconto.

Percebe-se que o VPL é a soma algébrica dos valores presentes positivos com os negativos. Para um investimento ser viável, o valor do VPL precisa ser positivo (ou maior que zero), demonstrando que há um domínio dos valores presentes dos ganhos em relação aos custos (HIRSCHFELD, 2000). Portanto, esse método é considerado um indicativo de lucratividade por ser capaz de demonstrar o valor do futuro calculado no presente, sem precisar realizar o investimento, evitando assim perdas monetárias.

\section{MÉTODO DA ANUIDADE EQUIVALENTE (AE)}

Ainda que o VPL seja um método muito válido para avaliar a viabilidade econômico-financeira de um investimento, ele precisa ser combinado com outras ferramentas de análise, pois não responde todas as perguntas sobre as incertezas de abrir um novo empreendimento (SAMANEZ, 2010). O autor destaca que é considerado um método mais prático do que aqueles que fazem repetições sucessivas ou 
substituições. Ele mostra como a renda gerada seria distribuída ao longo dos anos, se esta fosse equitativa. Assim, consistindo, basicamente, em uma divisão do VPL pelos anos de vida útil de duração do projeto, convertendo-se em uma série uniforme equivalente, podendo ser calculada pela Equação (2) a seguir:

$$
A E=\frac{V P L}{F V A}
$$

Onde, $F V A$ significa fator de valor atual e é conforme a Equação (3):

$$
F V A=\frac{(1+i)^{n}-1}{(1+i)^{n} * i}
$$

TAXA INTERNA DE RETORNO (TIR)

A Taxa Interna de Retorno (TIR) faz o equilíbrio do valor presente das saídas e entradas de caixa, ou seja, é a taxa de juros onde os lucros se equivalem aos custos (NEWNAN; LAVELLE, 2000).

Normalmente, em um investimento inicial temos um fluxo de caixa negativo devido a um empréstimo ou financiamento, e a medida que o tempo vai passando esse fluxo passa a ser positivo.

Quando aplicada ao cálculo do VPL, o fluxo, então, torna-se zero, podendo ser descrita pela Equação (4) (VIEIRA SOBRINHO, 2011).

$$
F C o-\sum_{j=1}^{n} \frac{F C o}{(1+i)^{j}}=0
$$

Onde:

$i=$ taxa da TIR; $F C_{o}=$ fluxo de caixa.

Sua maior vantagem é refletir a rentabilidade do capital em um projeto de investimento, e a forma de ser analisada é sendo comparada com a TMA. Se o resultado que a TIR apresentar for igual ou maior do que a TMA, o investimento é economicamente viável, ao contrário disso o projeto não será rentável (QUINTANELLA, 2011).

\section{PAYBACK}

De acordo com Neto (2010), o Payback indica em quanto tempo o capital investido inicialmente vai ser recuperado a partir dos lucros líquidos de caixa.

Seu cálculo é extremamente simples, porém seu nível de precisão é baixo devido ao fato de não levar em consideração o fluxo de caixa de retorno do capital empregado (PUCCINI, 2007).

Atualmente, existem duas formas principais de paybacks que são a simples e a descontada. A fórmula da payback descontada é mostrada pela Equação (5) (SAMANEZ, 2010):

$$
I=\frac{\sum F C}{(1+i)^{n}}
$$




\section{MATERIAIS E MÉTODOS}

Todos os cálculos necessários para a realização deste trabalho foram feitos avaliando duas situações distintas, as quais são o modelo de produção própria e o modelo de terceirização da produção. No modelo de produção própria, o estudo foi baseado na abertura de uma microcervejaria artesanal com uma capacidade de produção de 5000 litros de cerveja por mês e apresentado sob três cenários diferentes:

1. Otimista - com uma produção e venda de 60000 litros por ano $(5000 \mathrm{~L} / \mathrm{mês})$;

2. Pessimista - com uma produção e venda de 18000 litros por ano (1500 L/mês);

3. Realista - com uma produção e venda diferentes ao decorrer do ano, devido a diminuição do consumo de cerveja nos meses mais frios do ano. Foram considerados cinco meses de produção e venda total, e nos outros sete meses uma redução para 2200 litros por mês, resultando em uma produção e venda anual de 40400 litros.

Nesse contexto, para conseguir avaliar qual modelo de produção é mais viável financeiramente, o modelo de terceirização da produção considerou a mesma quantidade de vendas anual do cenário realista, que é de 40400 L/ano.

No modelo de produção própria, o preço de venda foi considerado de R $\$ 11,00$ o litro no barril e no modelo de terceirização da produção, o preço de compra da cerveja já envasada e rotulada foi de $\mathrm{R} \$ 6,20$ e o preço de venda em R\$10,00.

Para este trabalho, a TMA utilizada foi a taxa de juros referente ao Sistema Especial de Liquidação e de Custódia, mais conhecida como taxa Selic (RECEITA FEDERAL, 2018) que atualmente está em 6,50\%, sendo atualizada a cada 45 dias.

\section{RESULTADOS E DISCUSSÕES}

\section{MODELO DE FÁBRICAÇÃO PRÓPRIA}

\section{Investimento Inicial}

A Tabela 4 abaixo demonstra todos os investimentos iniciais necessários para a abertura de uma microcervejaria com capacidade máxima de produção de 5000 litros por mês.

Tabela 4 - Investimentos iniciais da microcervejaria.

\begin{tabular}{ccccc}
\hline Item & Capacidade & Quantidade & Custo unitário (R\$) & Custo total (R\$) \\
\hline Cozinha brasagem & $300 \mathrm{~L}$ & 1 & $29.900,00$ & $29.900,00$ \\
\hline Fermentador auto refrigerado & $1000 \mathrm{~L}$ & 4 & $38.500,00$ & $154.000,00$ \\
\hline Barril de chopp tipo "s" & $30 \mathrm{~L}$ & 30 & 460,00 & $13.800,00$ \\
\hline Barril de chopp com tubo sifão & $50 \mathrm{~L}$ & 70 & 670,00 & $46.900,00$ \\
\hline
\end{tabular}




\begin{tabular}{|ccccc}
\hline $\begin{array}{c}\text { Lavadora de barril } \\
\text { Cilindro de } \mathrm{CO}_{2}+\text { kit regulador de } \\
\text { pressão e mangueiras }\end{array}$ & - & 1 & $9.200,00$ & $9.200,00$ \\
$\begin{array}{c}\text { Cilindro de } \mathrm{CO}_{2}+\text { kit regulador de } \\
\text { pressão e mangueiras }\end{array}$ & $25 \mathrm{~kg}$ & 30 & 629,00 & $18.870,00$ \\
\hline Moedor de malte & $8 \mathrm{~kg}$ & 1 & $1.350,00$ & $5.400,00$ \\
Câmara fria & - & 1 & $2.850,00$ & $2.850,00$ \\
\hline Chopeira elétrica & $80 \mathrm{~L} / \mathrm{h}$ & 30 & $26.000,00$ & $26.000,00$ \\
\hline Itens diversos & - & - & $3.500,00$ & $105.000,00$ \\
\hline Total & & & - & $10.000,00$ \\
\hline
\end{tabular}

Fonte: Construção do autor.

\section{Custos e despesas}

As Tabelas 5 e 6 trazem a comparação dos custos e das despesas mensais de cada cenário. O cenário realista está relacionado a maior ou menor produção de cerveja e, então, ressalta-se que o cenário 3.1 é o demonstrativo do realista referente aos cinco meses de maior produção e o cenário 3.2 aos sete meses de menor produção.

Tabela 5 - Custos da microcervejaria.

\begin{tabular}{ccccc}
\hline \multirow{2}{*}{ Custos } & \multicolumn{4}{c}{ Valores (R\$) } \\
\cline { 2 - 5 } & Cenário 1 & Cenário 2 & Cenário 3.1 & Cenário 3.2 \\
\hline Água & 700,00 & 210,00 & 700,00 & 280,00 \\
Luz & $3.000,00$ & 900,00 & $3.000,00$ & $1.200,00$ \\
Gás & $1.600,00$ & 480,00 & $1.600,00$ & 640,00 \\
Gelo & 300,00 & 90,00 & 300,00 & 120,00 \\
Total & $5.600,00$ & $1.680,00$ & $5.600,00$ & $2.240,00$ \\
\hline
\end{tabular}

Fonte: Construção do autor.

Tabela 6 - Despesas da microcervejaria.

\begin{tabular}{|ccccc}
\hline \multirow{2}{*}{ Despesas } & \multicolumn{4}{c}{ Valores (R\$) } \\
\cline { 2 - 5 } & Cenário 1 & Cenário 2 & Cenário 3.1 & Cenário 3.2 \\
\hline Telefone & 50,00 & 50,00 & 50,00 & 50,00 \\
\hline Internet & 120,00 & 120,00 & 120,00 & 120,00 \\
\hline Aluguel & $2.500,00$ & $2.500,00$ & $2.500,00$ & $2.500,00$ \\
\hline Marketing & 730,00 & 730,00 & 730,00 & 730,00 \\
\hline Material limpeza & 790,00 & 790,00 & 790,00 & 360,00 \\
\hline Frete & $1.000,00$ & 500,00 & $1.000,00$ & 400,00 \\
\hline Cartório & 200,00 & 200,00 & 200,00 & 200,00 \\
\hline Tarifa bancária & 80,00 & 80,00 & 80,00 & 80,00 \\
\hline Manutenção & 800,00 & 400,00 & 800,00 & 320,00 \\
\hline Diarista & 600,00 & 400,00 & 600,00 & 600,00 \\
Combustível & 500,00 & 200,00 & 500,00 & 200,00 \\
\hline Contador & 375,00 & 375,00 & 375,00 & 375,00 \\
\hline Salário funcionários & $9.100,00$ & $4.000,00$ & $9.100,00$ & $9.100,00$ \\
\hline Pró-labore & $5.000,00$ & $4.500,00$ & $5.000,00$ & $5.000,00$ \\
\hline Total & $21.845,00$ & $14.845,00$ & $21.845,00$ & $20.035,00$ \\
\hline
\end{tabular}

Fonte: Construção do autor. 
Como pode ser observado, ambas as tabelas evidenciam que os custos e as despesas são proporcionais à venda e, consequentemente à produção.

\section{Fluxo de Caixa}

O fluxo de caixa é construído através da diferença entre as entradas e saídas mensais. As saídas estão representadas acima pelas Tabelas 5 e 6, e as entradas são as vendas da cerveja. Está sendo considerado apenas a venda da cerveja em barris de 30 e 50 litrosa um custo de $\mathrm{R} \$ 11,00$ o litro.

Tabela 7 - Fluxo de caixa anual e mensal dos respectivos cenários.

\begin{tabular}{ccccc}
\hline \multirow{2}{*}{$\begin{array}{c}\text { Fluxo de } \\
\text { Caixa }\end{array}$} & Cenário 1 & Cenário 2 & Cenário 3.1 & Cenário 3.2 \\
\cline { 2 - 5 } Mensal & $27.555,00$ & $-25,00$ & $27.555,00$ & $1.621,40$ \\
Anual & $330.660,00$ & $-300,00$ & $137.775,00$ & $11.349,80$ \\
\hline \multicolumn{5}{c}{ Fonte: Construção do autor. }
\end{tabular}

VPL

Como em qualquer projeto, os equipamentos utilizados possuem um tempo de vida útil devido ao esforço em que são submetidos diariamente. O tempo de vida útil que está sendo empregue nesta análise é de seis anos. Esse tempo é fundamental para o cálculo do VPL, pois ele vai medir o valor presente dos fluxos de caixa gerados pelo projeto ao longo desse período. A Tabela 8 traz os resultados obtidos para o cálculo dos diferentes cenários.

Tabela 8 - Valores do VPL ao longo de seis anos.

\begin{tabular}{cc}
\hline Cenário & VPL (R\$) \\
\hline 1 & $1.178 .809,50$ \\
2 & $-423.372,30$ \\
3 & $299.995,18$ \\
\hline Fonte: Construção do autor.
\end{tabular}

Como podem ser observados, os cenários 1 e 3 seriam viáveis economicamente, se baseados no cálculo do VPL, pois apresentam um valor positivo. O que não é o caso do cenário 2, pois, ao longo dos seis anos em que foram calculados, os investimentos iniciais não seriam pagos e a dívida só aumentaria. 
AE (Anuidades Equivalentes)

A Tabela 9 mostra as anuidades equivalentes para cada cenário, demonstrando qual seria o fluxo de caixa anual desse projeto ao longo desses seis anos iniciais.

Tabela 9: Valores da AE.

\begin{tabular}{cc}
\hline Cenário & AE $(\mathbf{R} \$)$ \\
\hline 1 & $243.504,70$ \\
2 & $-87.455,30$ \\
3 & $61.969,50$ \\
\hline Fonte: Construção do autor.
\end{tabular}

No cenário pessimista, não só os fluxos de caixa mensais são negativos como também o fluxo de caixa anual, confirmando, nesse caso, a inviabilidade do projeto, pois a dívida só aumentaria com o passar dos anos.

TIR

Pelo seu cálculo ser um pouco mais complexo, a TIR demonstra se a taxa oferecida pelo investimento é ou não atrativa. A ferramenta utilizada para calcular este índice - ou fator - foi a calculadora financeira HP. A Tabela 10 abaixo mostra as diferentes taxas encontradas para os diferentes cenários.

Tabela 10 - Valores da TIR.

\begin{tabular}{cc}
\hline Cenário & TIR (\%) \\
\hline 1 & 75,71 \\
2 & - \\
3 & 26,87 \\
\hline Fonte: Construção do autor.
\end{tabular}

Como a TMA fixada para esse projeto foi 6,5\% ao ano, ambos os cenários 1 e 2 seriam atrativos financeiramente. Por apresentar valores de VPL e fluxo de caixa anual negativo, o cálculo para a TIR do cenário 2 foi inconclusivo.

\section{Payback descontado}

O payback descontado leva em consideração também a TMA, que neste caso é de $6,5 \%$ ao ano. A Tabela 11 traz os valores calculados e manifesta qual seria o momento em que a dívida inicial seria quitada e o momento em que o projeto começaria a trazer somente lucros. 
Tabela 11 - Valores do payback descontado.

\begin{tabular}{ccccc}
\hline \multirow{2}{*}{ Cenário } & \multicolumn{4}{c}{ Payback (R\$) } \\
\cline { 2 - 5 } & Ano 1 & Ano 2 & Ano 3 & Ano 4 \\
\hline 1 & $310.478,90$ & $602.008,30$ & $875.744,90$ & $1.132 .775,00$ \\
2 & $-281,69$ & $-546,19$ & $-794,54$ & $-1.027,74$ \\
3 & $140.023,30$ & $271.500,60$ & $394.953,40$ & $510.871,50$ \\
\hline \multicolumn{5}{c}{ Fonte: Construção do autor. }
\end{tabular}

Fonte: Construção do autor.

Como o investimento inicial foi de $\mathrm{R} \$ 421.920,00$, nota-se que no cenário 1 esse valor já seria pago no segundo ano de projeto, enquanto que no cenário 3 que é o mais realista, a dívida seria paga em 4 anos. Este período é antes mesmo do tempo de vida útil dos equipamentos, o que é vantajoso economicamente. Em contrapartida, no cenário 2 a dívida só aumentaria a cada ano, o que o tornaria inviável em comparação com os demais.

\section{MODELO DE TERCEIRIZAÇÃO DA PRODUÇÃO}

\section{Investimento Inicial}

Como trata-se de uma terceirização da produção, não é necessária a compra de equipamentos para produção da cerveja. O único investimento inicial considerado é um veículo automotor no valor de $\mathrm{R} \$ 100.000,00$, para a realização de possíveis entregas.

\section{Custos e despesas}

Na terceirização não há os custos referentes à produção, apenas algumas despesas que foram retratadas na Tabela 12 .

Tabela 12 - Despesas da terceirização.

\begin{tabular}{cc}
\hline Despesas & Valor $(\mathbf{R} \mathbf{)}$ \\
\hline Telefone & 50,00 \\
\hline Internet & 120,00 \\
\hline Aluguel & $1.500,00$ \\
\hline Marketing & 500,00 \\
\hline Cartório & 200,00 \\
\hline Tarifa bancária & 80,00 \\
\hline Diarista & 200,00 \\
\hline Combustível & $1.000,00$ \\
\hline Total & $3.650,00$ \\
\hline
\end{tabular}

Fonte: Construção do autor. 
Considerando que é realizada a compra da cerveja já envasada e rotulada por R \$ 6,20 o valor do litro, e revendida por $\mathrm{R} \$ 10,00$, tem-se um lucro de $\mathrm{R} \$ 3,80$. Nos cinco meses em que a compra e venda são de $5000 \mathrm{~L} /$ mês, o fluxo de caixa mensal é de R \$ 15.350,00. Já nos meses restantes, em que a venda é diminuída, com apenas 2200 L/mês, o fluxo de caixa é de R $\$ 4.710,00$, totalizando em um fluxo de caixa anual de R\$109.720,00.

VPL

Embora o veículo utilizado não tenha uma vida útil tão curta, para fins comparativos o cálculo do VPL foi realizado para seis anos. O valor encontrado foi de $\mathrm{R} \$ 431.156,01$, apontando a viabilidade do investimento.

$\mathrm{AE}$

O fluxo de caixa anual encontrado para esse modelo, durante o período de seis anos, foi de R\$ $89.063,17$. Por ser um valor superior comparado ao cenário 3, sugere-se que este investimento tenha uma viabilidade econômico-financeira maior.

TIR

A TIR encontrada para esse modelo foi de 108,38\%, expressando um aumento muito significativo se comparado ao cenário 3 , indicando uma maior atratividade, pois a taxa mínima admitida para o investimento ser atrativo ou não foi de $6,5 \%$.

\section{Payback descontado}

A Tabela 13 abaixo traz o demonstrativo do cálculo de payback descontado para o mesmo período de quatro anos.

Tabela 13 - Valores do payback descontado.

\begin{tabular}{cc}
\hline Ano & Payback descontado (R\$) \\
\hline 1 & $103.023,47$ \\
2 & $199.759,13$ \\
3 & $290.590,73$ \\
4 & $375.878,62$ \\
\hline \multicolumn{2}{c}{ Fonte: Construção do autor. }
\end{tabular}


Como pode ser observado na tabela acima, o investimento inicial já seria pago no primeiro ano de funcionamento do projeto, pois o valor encontrado do payback para o primeiro ano foi de $\mathrm{R} \$ 103.023,47$, demonstrando que a dívida inicial de $\mathrm{R} \$ 100.000,00$ seria paga e ainda sobraria uma parcela do valor.

\section{CONCLUSÕES}

Com o presente trabalho, foi possível avaliar a viabilidade econômico-financeira da produção de cerveja artesanal sob dois aspectos diferentes: o de produção própria e o de terceirização da produção. Para o primeiro caso, três cenários distintos foram retratados, o otimista, o pessimista e o realista, pois, nenhuma dessas situações estão livres de acontecer. Ficou nítida a maior viabilidade no primeiro cenário, com os valores altos de fluxo de caixa anual, VPL, AE e uma TIR bastante atrativa, porém, como o nome do cenário já sugere, ele é otimista e próximo da irrealidade, pois as vendas não serão uniformes tão rapidamente. O segundo cenário, o pessimista, também foi apresentado, pois essa é uma realidade de muitos negócios que foram mal planejados e terminaram falindo nos primeiros anos de funcionamento. Por fim, foi possível verificar que o cenário realista foi o que mais se aproxima da realidade possível, principalmente por se tratar de um estudo realizado para abertura de uma microcervejaria na cidade de Santa Maria, onde temperaturas baixas são frequentes e o consumo de cerveja decai em decorrência disto. Neste caso, o modelo realista de produção própria demonstrou-se, através dos indicadores de viabilidade, ser um investimento atrativo economicamente. Porém, em comparação com a terceirização da produção, esse modelo apresenta-se mais viável economicamente, uma vez que os valores dos cálculos dos indicadores foram todos superiores e, principalmente pela TIR ser de 108,38\%. Entretanto, mesmo que sejam realizados todos os cálculos e estudos necessários de viabilidade econômico-financeira para abertura de um novo empreendimento, ressalta-se que sempre podem haver algumas eventualidades que não poderão ser previstas, reforçando a necessidade de um estudo detalhado de caso.

\section{REFERÊNCIAS}

DAMODARAN, A.; AVALIAÇÃO DE INVESTIMENTOS: Ferramentas e Técnicas para a Determinação do Valor de Qualquer Ativo. 2. ed. Qualitymark, 2010.

DELGADO, Y. L.; Plano de negócio para microcervejaria artesanal. 2016. 84 folhas. Monografia (Trabalho de Conclusão de Curso em Administração) - Escola de Administração, Universidade Federal do Rio Grande do Sul, Porto Alegre, 2016. 
HIRSCHFELD, H.; Engenharia econômica e análise de custos: aplicações práticas para economistas, engenheiros, analistas de investimentos e administradores. 7. ed. São Paulo: Atlas, 2000.

MAPA - Ministério da Agricultura, Pecuária e de Abastecimento. Anuário da cerveja no Brasil 2018. 2019. Disponível em: https://bit.ly/3aeyCqd. Acesso em: 24 jun. 2019.

MARTINS, E.; Contabilidade de custos. 9. ed. São Paulo: Atlas, 2003.

MORADO, R.; Larousse da Cerveja. 1. ed. São Paulo: Alaúde, 2017.

NETO, A. A.; Finanças Corporativas e Valor. 4. ed. São Paulo: Person 2010.

NEWNAN, D. G.; LAVELLE, J. P.; Fundamentos de Engenharia Econômica. 1. ed. Rio de Janeiro: LTC, 2000.

PUCCINI, A. L.; Matemática financeira: Objetiva e aplicada - 7. ed. - São Paulo: Saraiva, 2007.

QUINTANELlA, M.; Análise de Projetos e Investimentos. FGV Management. MBA em Gestão Financeira, Controladoria e Auditoria. 2011.

Receita Federal - Ministério da Fazenda. Taxa de Juros Selic, 2018. Disponível em: https://bit.ly/ 2wOZL1Y. Acesso em: 02 nov. 2018.

ROCHA, E. G.; SOUZA, C. A.; DALFIOR, V. A. O.; Estudo da viabilidade econômica financeira: caso modelo. Edificação em São João Del Rei - Minas Gerais, 2015.

SAMANEZ, C. P.; Matemática financeira. 5. ed. Editora Pearson/Prentice Hall, 2010.

VIEIRA SOBRINHO, J. D.; Matemática financeira. 7. ed. - 13. reimp. São Paulo: Atlas, 2011. 